\title{
ESTUDOS SOBRE APRENDIZAGEM ORGANIZACIONAL
}

A aprendizagem organizacional é um campo de estudo estabelecido, cuja discussão central está no conhecimento e em sua apropriação pela organização, bem como na noção de mudança contínua. Neste vasto campo, alguns autores relacionam os estudos de aprendizagem ao desenvolvimento de competências organizacionais. Neste caso, o resultado é a aquisição de uma competência para aplicar novos conhecimentos ao aprimoramento de performance de atividades existentes ou para o preparo para novas circunstâncias. A professora Adriana R. W. Takahashi, da UFPR, oferece indicações que podem auxiliar no entendimento do tema.

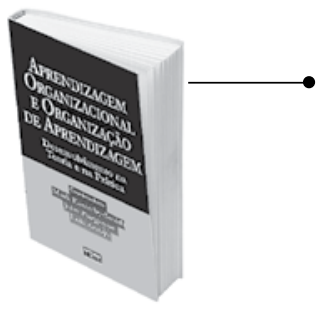

APRENDIZAGEM ORGANIZACIONAL E ORGANIZAÇÃO DE APRENDIZAGEM: desenvolvimento na teoria e na prática. Mark Easterby-Smith, John Burgoyne e Luis Araujo. São Paulo: Atlas. 2001. 301 p.

Organizado em duas partes, este livro trata da aprendizagem organizacional e das organizações de aprendizagem sob a perspectiva técnica e social. Na primeira parte, os artigos trazem importante contribuição ao apontar dificuldades e limitações à construção do campo teórico e ao realizar uma revisão crítica da literatura existente. Já a segunda parte reúne estudos práticos de implementação da aprendizagem organizacional em ambientes organizacionais, com base em diversas metodologias de intervenção, mesclando teoria e prática.

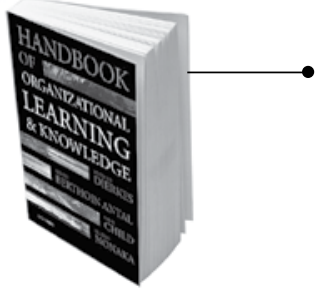

HANDBOOK OF ORGANIZATIONAL LEARNING \& KNOWLEDGE. Meinolf Dierkes, Ariane Berthoin Antal, John Child, and Ikujiro Nonaka (Eds). Oxford: Oxford University Press, 2001. 960 p.

Esta obra aborda o tema sob diferentes perspectivas. Os textos proporcionam o debate sobre como as organizações partilham, usam e retém conhecimento, assim como elas criam conhecimento. O livro é resultado de uma discussão entre autores de 16 países, que participaram de uma associação de estudos sobre aprendizagem organizacional entre 1994 e 1998. Dividido em quatro partes, com 42 capítulos, o livro termina com uma reflexão sobre a dinâmica do campo e os desafios para o futuro dos estudos em aprendizagem organizacional e conhecimento.

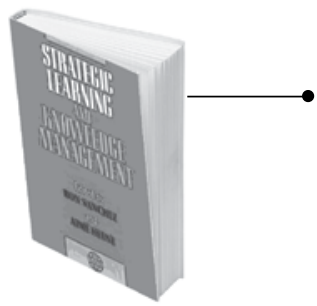

STRATEGIC LEARNING AND KNOWLEDGE MANAGEMENT. Ron Sanchez and Aimé Heene (Eds). West Sussex: John Wiley \& Sons Ltd.: 1997. 235 p.

Neste livro, os autores avançam nos estudos do campo ao introduzir uma perspectiva de aprendizagem organizacional e conhecimento relacionado à teoria de competências organizacionais e de competição baseada em competências. O ponto principal desta perspectiva é compreender como melhores enfoques de aprendizagem e utilização de conhecimento podem melhorar o processo de construção e alavancagem de competências das organizações.

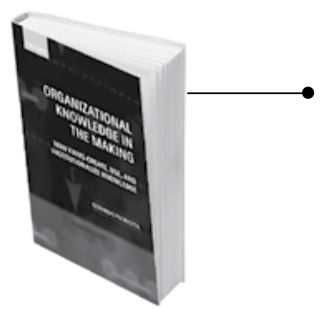

ORGANIZATIONAL KNOWLEDGE IN THE MAKING: how firms create, use, and institutionalize knowledge. Gerardo Patriotta. Oxford: Oxford University Press, 2003. 232 p.

Neste livro, Patriotta argumenta que estudar o conhecimento nas organizações é como procurar silêncio em um mundo de barulho. Para compreender tal fenômeno, ele argumenta que uma nova ênfase deve ser dada na dinâmica da institucionalização do conhecimento, pois muito já foi dito sobre sua criação e utilização. A fim de preencher esta lacuna, desenvolve um estudo empírico em duas plantas industriais da Fiat. O estudo enfatiza o processo de construção e evolução, em vez de conversão, e evidencia uma relação entre competências e aprendizagem.

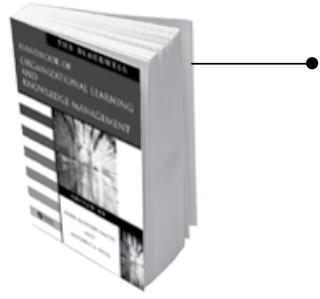

THE BLACKWELL HANDBOOK OF ORGANIZATIONAL LEARNING AND KNOWLEDGE MANAGEMENT. Mark EasterbySmith and Marjorie A. Lyles (Eds). London: Blackwell, 2003. 676 p.

Esta coletânea mapeia o estado da arte em aprendizagem e conhecimento organizacional. Os autores categorizam quatro campos de estudo, em função dos eixos processo-conteúdo e teoria-prática: aprendizagem organizacional, organizações de aprendizagem, conhecimento organizacional e gestão do conhecimento. Então, identificam trabalhos clássicos, trabalhos de fundação e trabalhos populares como 'divisores de águas' de cada vertente. No último capítulo ainda reafirmam a legitimidade das pesquisas do tema e formulam uma agenda para futuras pesquisas. 